\title{
Theorising a transformative agenda for craft
}

\author{
By Matthew Kiem
}

Matthew Kiem is a session lecture/tutor in design studies at UTS: Insearch. He has also worked at COFA, UTS, and Whitehouse Institute of Design. Matthew's work as a researcher, writer, and educator focuses on issues in the theory and practice of designing for sustainable futures. He is a member of the Sydney based Project Otherwise group, and a participant in Odessy, the project of redirecting design thinking and practice towards sustainment.

Abstract: This paper examines the potential of craft to facilitate cultures of quality and social transformation in the interests of sustainability. This approach is theoretically grounded in the work of Tony Fry. It draws particularly on his concepts of sustain-ability and Sustainment to construct an argument for what is both valuable about craft as a practice of material fabrication, and what broader social goals craft practitioners might set themselves in recognition of this value. The transformative potential of craft is explored through David Harvey's dialectical theory of social transformation.

This exploration of the potential of craft is also coupled with a recognition of current constraints within contemporary craft practices. In particular, the role of craft within practices of symbolic production and exchange is critiqued through the work of Jean Baudrillard and Pierre Bourdieu. Through these thinkers we observe how crafted artifacts are denied their sustaining potential and how craft practitioners themselves may become absorbed in facilitating the negation of craft as Sustainment. By way of conclusion it is proposed that in order to realise both the sustaining and transformative potential of craft, practitioners must develop a capacity for ongoing critical reflection that informs vocational commitment to change through craft practice. In this capacity, it is a call for practitioners to both recognise and engage with the political agency of craft as a way of fabricating new, and more sustainable modes of (human)being.

\section{Paper}

\section{Introduction}

'Think of objects that are beautiful and useful as trees in your own garden, objects that endure and have lives of their own, objects that perform services and require care (Manzini 1995:239).' 
The aim of this paper is to contribute to an understanding of craft as Sustainment. The theoretical background of this framing comes predominantly from the work of design theorist Tony Fry. Drawing upon the philosophical thinking of Martin Heidegger, Fry examines how the way in which we prefigure and construct our artificial environments conditions our sense of being-in-the-world (Fry 1999, 2009; Heidegger 1962). In thinking through the consequences of design as an ontological force, Fry has opened important avenues for critiquing the role of design in constructing the condition of human unsustainability.

Fry argues that contemporary practices of design and manufacture, including fashion design, planning, architecture, industrial design, visual communication, and of course, craft practices, engender unsustainability as a particular mode of being (Fry 2007a: 20). This is to say that unsustainability has been constructed and normalised through the material and symbolic effect of advertising, consumer products, infrastructure, military design, entertainment industries, and so on. The crisis of unsustainability is understood by Fry not as a question of 'saving the planet'. Rather, it is a question of how institutionalised ways of being degrade the relational ensemble of social, technical, and biological ecologies that humans depend upon. This structural negation of our condition of being dependent on people, things, and systems is a thoroughly designed phenomenon (Fry 1999).

By physically and symbolically constructing our worlds according to our current imaginative desires and dispositions we degrade both our ability to sustain and our ability to see the impact of our actions. Designing and making is therefore directional, in that it creates and negates possible futures, and political, in that it creates and negates certain arrangements of power. This makes any practice of production and consumption an important object of critical examination as it is both a product of an historical conditioning, and a way of conditioning the possibilities of future action.

This theoretical background delivers the object of my concern here with craft. Just as we may identify design as a source of ontological transformation, it is also possible to identify craft as a mode of production that gathers and shapes a particular manner being-in, of, and towards the world. In perhaps simpler terms, we can identify that craft practice generates a qualitative reality of a certain character, both in the labour itself and though the artifacts it may produce (Fry 1994: 96). In narrowing the concern towards what may be significant about craft specifically, David Pye's distinction between design and workmanship becomes helpful (Pye 1968: 1). Whereas design imaginatively prefigures and represents the future existence of a thing, system or behaviour, workmanship involves the material realisation of an imagined design. The character of this activity is discussed in terms of what it might contribute to sustaining long term human futures.

In being both directional and political craft contains the power to either prolong or transform conditions we acknowledge are unjust and damaging to the health and flourishing of human and non-human others. As such there is also a need to 
examine the condition of contemporary craft practice. In this regard an argument for both the potential of craft as Sustainment and the constraints of current practice will be made. The conclusion of this argument is that the sustainability of craft is potentially significant, but this is restricted by the structural conditions within which it is practiced. It follows that in order for craft to become a transformative force, practitioners must develop a critically informed, practice based commitment to assert the sustaining value within craft. That is to say, craft practitioners must learn to facilitate the redirection of their own practice in order for craft to become a force for Sustainment (Fry 2009).

\section{Sustain-ability and Sustainment}

Before proceeding with the body of the argument it would be helpful to spend some time elaborating on some of the key concepts used in this paper that originate from Fry's work. Against the background of his critical comments on the use of the term 'sustainability', Fry uses the term 'sustain-able' to emphasise an ability to sustain that is embodied in the relationship between people and things (Fry 1999: 8; 2007c). A similar description of this relationship between people and things can be recognised in the concept of 'distributed competence', which is derived in part from actor-network theory (Latour 2005; Shove et al. 2007). These theories suggest that the knowledge we draw upon to achieve any practical objective is not accounted for by considering the capacity of only individual human subjects. Rather, practical ability exists as distributed both through social relationships and everyday pieces of equipment and technology.

For instance, Shove identifies how the projects of domestic DIY practitioners succeed not only because of individual skill, but also through the advice of friends and experts, and what may be achieved with particular tools and materials (Shove et al. 2007: 55). As a specific example, quick drying, non-drip paint that 'knows' how to go onto a door represents a technological embodiment of the skill of an expert painter (Shove et al. 2007: 55). This characteristic affords an amateur the ability to achieve a quality of finish otherwise beyond his or her level of skill. Ability should therefore be understood as the product of an assemblage of social relationships and material things.

While this concept of distributed competence in itself does not represent the same meaning of sustain-ability, as an explanation that decentres the primacy of individual human subjectivity it provides an example of the way in which an ontology is conditioned by a relation to a world of equipment. Understanding the nature of this relationship between people and things is an important feature of sustain-ability, as it avoids the pitfalls of understanding 'sustainability' as a quality that might exist in objects regardless of their context of use. 'Sustainability' also implies that particular materials, such as wood, cannot be regarded as essentially 'sustainable' for merely representing the possibility of a sustainable metabolic cycle (Fry, 1999: 8). Rather, by allowing us to talk in terms of the ability of individuals, groups, and their relation to the built world, 'sustainability' assists us in thinking beyond the mere technical specifications of objects, 
and onto questions of how an endemic condition of cultural unsustainability is symbolically and materially constituted, and what kind of designing and making may begin to counter this condition.

Developing sustain-ability is a project directed at establishing a condition of Sustainment. Fry uses the concept of Sustainment to refer to a state in which the total inertia of human socio-technical existence, including cultures and economies, act to secure rather than damage the possibility of long term futures. The Sustainment may be equated in scale with the epochal shift of the 18th century Enlightenment movement which founded many of the concepts and institutions that persist into the 21st century (Fry 2004: 36). As such, Sustainment suggests an immense cultural project, encompassing changes to everything that underscores our sense of being-in-the-world, including economies, material and symbolic structures, knowledge, embodied experience, and social relations. As a concept, 'the Sustainment' works as a singular goal towards which practitioners of otherwise heterogeneous disciplines (including artists, designers, architects, craft practitioners, educators, researchers and writers) may orientate a political commitment.

While the significance of Sustainment to present craft practitioners calls for further articulation, I will delay this for a later examination of the dynamics of large scale social change. With these introductory concepts in place we can now turn to the potential role of craft within a condition of Sustainment.

\section{Craft and Sustainment}

In the chapter 'Prometheus of the Everyday', Ezio Manzini argues that addressing the challenge of our unsustainability must be, at least in part, a concern with dematerialising our economies and daily practices (Manzini 1992: 230). More specifically dematerialisation would involve a greater shift from owning products to using services; an increase in facilities of repair, upgrade, and renting; the minimisation of negative impacts in the lifecycle of products; reuse and recycling; and finally, elongating the useable lifespan of products (Verbeek \& Kockelkoren 1998: 29). These changes, rather than being marginal reforms, would constitute new environments of human habitation and produce new cultures of manufacture, usage, and wastage. In concluding his article, and as a way of describing how this alternative future might be experienced, Manzini offers a brief sketch of a scenario he names the 'garden of objects' (Manzini 1992: 239). This 'garden of objects' represents a condition in which our interaction with the material things of our everyday world is like that of the relationship between a garden and gardener. This encapsulates the idea that through a practice of tending to the health of plants and things, a deep sense of wealth and satisfaction may emerge. Furthermore, the experience of this world names something more than the mere satisfaction of brute needs, economic interest, or a concern for calculable efficiency and frugalness. Rather, it describes a disposition for care, wisdom, and respect towards our material/ temporal existence that enables what is truly important to flourish and endure. 
The line of argument in 'Prometheus of the Everyday' focuses primarily on the potential of design to facilitate a transitioning towards more sustainable modes of socio-technical being. In addressing the issue of sustainability it is appropriate that Manzini would focus on design, for design's prefigurative function is a powerful form of agency as both a driver of the unsustainable and as a potential force for future redirection (Fry 1999, 2009: 29-51). There are also reasons why design is significant to craft. Firstly, all practitioners must work with a prefigured understanding of what they have committed themselves to bringing into being, even if at times this may be a vague and emergent experience. Secondly, design not only represents the guiding image of any particular work, but, in a much more primordial sense, it is an activity that conditions our sense of being-inthe-world (Fry 1999, 2009; Heidegger 1962). This is to say that design has an ontological effect that is deeply significant for how craft is practiced. As the act of (pre)forming the character of our material and symbolic environments, design works upon us and itself in an hermeneutic fashion so that we may say that design designs (our) designing (Fry 1999; Willis 2007). Design is therefore both implicit within, and a constitutive element of any form of craft practice.

In these ways design is indivisible from craft. Yet there are particular characteristics of craft that still call to be identified and understood in themselves and in relation to Sustainment. As David Pye has demonstrated, in any material artifact there is something distinctive and significant about the workmanship involved that is irreducible to the act of it being designed (Pye 1968: 1). The distinctiveness that Pye observes is that between design as a representation of something in the ideal for the purposes of making, and workmanship as the ability to execute the fabrication of a design; 'design proposes, workmanship disposes' (Pye 1968: 1).

The significance of workmanship, that is, what it makes possible when it is either good or bad, and the ontological consequence it has for both craft practitioner and user, appears underrepresented within Manzini's vision. While we might recognise Manzini's scenario as a something like a condition of Sustainment, what would be fundamentally necessary for a 'garden of objects' to work is, firstly, a certain material quality of the things that would make up this world, and secondly, practices that would foster what we might call 'cultures of quality'. By cultures of quality I mean complex and highly attuned practices of workmanship that incorporate a deep concern for the sustain-ability of people, practices, and equipment. The claim being made here is that the health of a 'garden of objects' is dependent upon the development - and in some instances a re(newed) development - of the kinds of socio-technical modes of being that exist within various craft practices. In short, in order to enrich the interpretation of Manzini's vision of a more inhabitable everyday material environment, it is important to understand the potential of craft as a Sustainment practice, and particularly, how it might facilitate cultures of quality. 


\section{Cultures of (sustain-able) quality}

Manzini has indeed argued that making the transition toward something like a condition of Sustainment we would require the development of cultures that sustain practices of sophisticated material understanding (Manzini 1992; Tonkinwise: 2004: 65). An example of this need is evident in the case of growing one's own food. Locally produced food does have potential as a sustain-able practice, but the benefits may be undercut if, for instance, a lack of experience leads to an unnecessary reliance on synthetic fertilisers and pesticides. To instill effective sustain-ability it is important to develop practices that hold, within a community of knowledge and things, the ability to produce minimally and consume fully the artefacts of labour. This is in contrast to our current condition which seeks to depress the value of labour in order to produce too many things that are impossible to fully consume, and are therefore irrevocably destined for wastage (Fry 2009: 192).

Fry outlines three ways that craft may contribute to what I mean by cultures of quality (Fry 1994: 98). Firstly, the experience and understanding developed through a craft practice can be significant in informing a more careful approach to the design and fabrication of products. Thinking this through more specifically, and in relation to sustain-ability, an experienced understanding of what certain materials are capable of, and what different forms, finishes, or other characteristics afford in terms of a thing's 'intentionality' (Verbeek \& Kockelkoren 1998: 36), has implications for the useful lifespan of a thing. Furthermore, this knowledge may inform planning for end of life scenarios that makes it easier to retrieve materials for reuse or recycling.

Secondly, craft practice may facilitate 'care in use'. This means that things may be designed and fabricated in such a way that ensures as best as possible the safety and health of their users. This may include considerations for the handling of the object, finishings, toxicity, and ease of use. It would also include consideration for objects as equipment for healthy and sustain-able activities. For instance, the careful forming of a surfboard may be thought of as act of materially fabricating a concern for the safety of surfers (making sure they have adequate control, buoyancy, grip etc.) and allowing them to engage in a healthy, fulfilling, low impact activity. Similarly, an expertgardener would be able to skillfully deploy an ensemble of equipment (spaces, tools, containers, irrigation systems etc.) to produce nutritious food without recourse to excessive use of power, water, or unnecessary fertilisers or pesticides.

The final point is a consideration for aesthetics, but not an aesthetics in the sense of considering the visible form of a thing. Rather, quality workmanship may play a key role in facilitating what Cameron Tonkinwise has described as 'beauty-in-use' (Tonkinwise 2004). Originating from the philosophy of Martin Heidegger, this counterpoint to dominant Western conceptions of the aesthetic recognises that when we use things, and they are working well for us, rather than standing before us as objects to be contemplated they recede into the background of our awareness and act to mediate our experience of the world 
(Tonkinwise 2004: 66). Heidegger uses hammering as an example of how a thing such as a hammer ceases to be experienced as a thing in itself (Heidegger 1962: 98). In use a hammer becomes fully incorporated as part of an individual's sense of hammering. The person using it does not consciously think they are holding a hammer and hammering, they are simply directed at driving nails into wood. Beauty-in-use attempts to understand the consequences of how to create things that, in receding from and mediating our attention, dispose us more easily towards the sustain-able. Beauty-in-use therefore stands in contrast to Platonist conceptions of ideal form which renders things as pure function or symbolic representation (Tonkinwise: 2004: 65; Verbeek \& Kockelkoren 1998); a conception that is incapable of considering the ontological consequences of things as material matter. This point underscores a critique of the aestheticisation of craft which will be taken up later.

Further to simply functioning well, beauty-in-use also concerns the facilitation of practices of care that extend the useful life of products. For instance, in moments of disrepair a thing like a hammer returns as an object of our attention, namely, as something that requires either repair or disposal. In these instances good and careful workmanship may facilitate a disposition to repair things rather than throw them away, a disposition that may arise from the value recognised in a finely crafted object and sense of commitment that can develop towards things in our lives that have served us well over a long period of time.

\section{Craft as ontological}

These considerations so far have looked at how craft might facilitate more sustain-able practices of production and use of things through the quality of both design and workmanship. However it is also important to emphasise that workmanship, both in the doing and the using, has a greater effect on us than simply meeting our needs. It also engenders particular experiences of beingin-the-world that are consequential for sustain-ability (Heidegger 1962: 78). Understanding how craft fosters modes of being requires consideration of its ontological impact.

To begin with the activity of crafting itself, working a material with tools under careful, experienced direction, has a twofold conditioning effect. Firstly there is a conditioning of the materiality of the world, understood as a totality of conditioned equipment. That is, craft can be an act of materialising the equipment that forms our world. From mere resource, the act of crafting procures a thingly state of being, that is, an equipmentality which is beheld by a conditioned (human) being, against and in relation to a world of equipment. As Heidegger explains, there is never such a thing as 'an equipment'; the being of a single piece of equipment can only be comprehensible in relation to a totality: 'Equipment ... always is in terms of its belonging to other equipment: ink-stand, pen, ink, paper, blotting pad, table, lamp, furniture, windows, doors, room' (Heidegger, 1962: 97). Therefore, the work of a craft practitioner is a way of being disposed within and towards the shaping of a world of equipment. 
Along with the being of equipment within the world, a second form of conditioning effected by craft is on the person themselves. To the individual practitioner, the actual labour of craft is all at once a mind/body/equipment/material involvement directed at an outcome. In action, whatever distinctiveness there is to these concepts is overridden by a practical foresight that gives regard only to the inertia of the task to hand. For instance, a master ceramist throwing a pot would be so attuned to their material and tools that they would give no conscious thought to adjusting the speed of the wheel or the pressure and position of the hand in touch with the clay. Hand and foot simply move with an embodied sensitivity that is able to guide a pot into being. While this activitycan be represented as a process or series of discrete steps, this representation of the act of labour cannot capture the non-propositional elements of skill, and may only really be useful as a starting point for beginners. In order to become fully adept at a skill such as throwing a pot, practitioners must work both their material and their body until rule-like behaviour becomes a habitual disposition.

This character of acquiring a skillful relation to tools and material is present in all acts of human guided labour, and is not simply limited to the traditional conceptions of craft. As Fry has stated: 'The qualification of craft practice is neither predicated upon established hand working, machine- based skills nor new methods which employ advanced technology but rather on the articulated relation between hand and mind in making which secures a direct human presence, as the loci of power and knowledge, in the made' (Fry 1994: 97).

Craft, therefore, is an activity which facilitates a certain experience of beingin-the world as an embodied being amidst material things in a relationship with other people. As such it is more than just an activity of making functional or symbolic objects. To further this idea in relation to Sustainment, we may begin to examine how these characteristics may work with a much broader transformative agenda in mind.

\section{Sustainment and co-revolutionary theory}

So far I have outlined ways in which craft has the potential to engender sustainability. As I described earlier, for Fry, this concept of sustain-ability is directed at establishing a general condition of Sustainment. In order to more fully understand the potential of craft as a transformative force directed towards establishing this condition it is useful to return again to Sustainment as a concept of broad scale social change. The link between the intimate activity of craft and social change appear may be large, but in conceptualising the relation of how micro- scale attempts at engendering sustain-ability may lead to a condition of Sustainment, I have found it helpful to use David Harvey's theory of co-revolutionary social change.

Harvey's theory attempts to explain the dynamic of transforming social orders (Harvey 2010). Reading from Marx's analysis of the transition from a feudal to 
capitalist mode of production, Harvey proposes that social change emerges as a flow of momentum that transforms seven 'moments' of social/economic reproduction. This 'assemblage of activities and practices' includes:

1. technological and organisational forms of production, exchange and consumption

2. relations to nature

3. social relations between people

4. mental conceptions of the world, embracing knowledges and cultural understandings and beliefs

5. labor processes and production of specific goods, geographies, services or affects

6. institutional, legal and governmental arrangements

7. the conduct of daily life that underpins social reproduction

While each of these moments proceeds with a certain degree of autonomy, as with the interconnected nodes of a spider's web any movement at a particular moment will provoke a corresponding change in each of the other moments. For instance, when the use of coal powered steam engines was adopted by manufacturers in England during the 18th century, manufacturers were freed from the previous constraints of human, animal, wind, and water power (Marx 1974:398). This technical innovation instigated a change in the relation to nature that also impacted on the organisation of production, the social relation of workers (particularly through the division of labour), and the factory form. Changes to the division of labour also increased the proportion and quantity of unskilled labour, and the rise of the factory system instigated new spatial dynamics, including a trend towards urbanisation.

In considering the changes that emanate from coal powered engines, even in these simplistic terms, it is important to retain a dialectal conception. The transformation of social orders under capitalism did not follow a strict causal process, but rather unfolded in a relational dynamic that had no definitive moment of beginning or end, and a propensity towards contradiction that continues to manifest in political, economic, environmental, or humanitarian crises. The dynamism of this dialectical ensemble exists not just during times of revolutionary change, but, as Harvey argues, persists as part of the ordinary conditions of a social order (Harvey 2010). In our own case, this is a social order characterised by the dominance of capitalism. What Harvey identifies as the driver of the capitalist mode of production - the provision of compound interest on investment - constantly tests the limits inherent within the production cycle, including the limits of resources, time, space, labour, technology, and finance. The pressure to grow in the face of limits fuels a constant program of innovation (Harvey 2010). As capitalism pushes against the limits of growth it exposes both its contradictions, but also its strength; a capacity to drive innovation in its own interest. Innovating in the face of limits also exposes the limits to our 
thinking on limitation, as, for instance, in relation to our sense of what may be or become 'resource' (Stables 2010: 140). Always however, it reveals the power of the institutions erected to protect economic growth (government, central banks, IMF, World Bank), which have the capacity to mobilise entire social orders in service of the needs of capital accumulation.

Harvey views the contemporary condition of capitalism as fundamentally incompatible with principles of fairness and sustainability, and champions a transition towards an alternative form of social arrangement. Whether or not we choose to take up Harvey's explicitly anti-capitalist stance- Fry, for instance, argues that Sustainment might involve a redirection rather than an overthrow of capitalism (2007c: 75) - Harvey's co-revolutionary theory provides a relational understanding of how a transition towards Sustainment may unfold. To the question of where such a movement might begin, the answer lies in the dialectical relation, that is, change must be initiated by individuals and groups at each moment of social reproduction. The activities of our daily life, our understanding of the world, our relation to other people, our ordinary work practices, our exchange practices, how we own and use equipment, each of these and more represent sites in which politicised craft practitioners may intervene with the intention of redirecting the force of our unsustainability.

\section{The semiotic trap}

Having briefly examined the transformative potential of craft it is worthwhile analysing the constraints of contemporary craft practice. An important area to confront is the role of craft as a symbolic artifact - as it exists for instance in service to the tourist industry, household furnishings, gift giving, and/or 'craft as art'. Jean Baudrillard for instance has examined the manner in which the political-economy of sign value has become the dominant characteristic of our contemporary material culture $(1981 ; 1996)$. He has argued that as capitalist economies matured the sign function of objects became key to practices of production and exchange, over and above conceptions of use-value or utility (Baudrillard 1981: 29). We may see evidence of this effect on craft when it is considered as a certain category of objects with symbolic attributes (for instance, as a sign of 'authenticity', 'tradition', 'the exotic', 'romantic indigenousness', 'anti-industrialism' etc.).

For example, in one social context, an antique table may stand as a reflection of the value of tradition, family, or cultural sophistication, whereas in another instance it may become the marker of a drab, conservative outlook. Under these conditions crafted things are taken up and deployed as part of a practice of symbolic representation, an activity that may thwart or deny the ability of workmanship to facilitate more sustain-able practices. Other symbolic uses of 'craft' may involve the romantic fictions that surround conceptions of indigenousness and the exotic European-Other, which are often deployed in the construction of national, or counter-(post)modernist identities, particularly within the souvenir and gift industries (Hickey 1997, Fry 1994: 90). 
On this particular point, while there are serious issues relating to the damage of cultural co-option, the nature of the power dynamics involved should not be reduced to a simple case of Westernised imposition upon passive populations. For instance, in Laos, the government works with the United Nations Educational, Scientific and Cultural Organization (UNESCO) to preserve the ancient capital of Luang Prabang as a World Heritage site (Long \& Sweet 2006). This includes the conversion of the old palace into a museum, and the preservation of both Buddhist temples and colonial era style buildings. Luang Prabang also hosts nighttime markets, where textile, wood, stone, and other 'craft' items are sold as gifts or souvenirs. Many of the products sold convey an aura of both exotic and traditional authenticity, even though they are designed and produced specifically for the tourist market. Beneath the romance of the tourist experience run tensions relating to the construction of a national identity following the ruptures of colonial intervention. The manufacture of Luang Prabang as a sign of Laos' past also facilitates a binary symbolic relation to the new capital, Vientiane, which, as the base for the socialist, anti-royalist state administration, becomes the legitimate locus for development agendas aimed at modernising the state (Long \& Sweet 2006: 469). Despite being far more complex than I can give representation to here, the situation in Luang Prabang at least begins to reveal otherwise undisclosed issues concerning what is currently sustained by existing craft practices.

In addition to Baudrillard's consideration for how craft objects may be consumed, Pierre Bourdieu's work on what he terms 'the field of cultural production' provides a perspective on the conditions of cultural and symbolic production. Bourdieu argues that the nature of fields within which cultural artefacts are produced - such as visual arts, music, theatre, or literature - can be characterised as a dynamic between two opposing poles (Bourdieu 1983). The dominant pole, the one that attracts the most symbolic power, is the autonomous realm of production, the space of 'art for art's sake'. In this form of social game, studio artists/craftspersons are involved in producing works that may stand as material manifestations of individual creative genius. The power of this realm is maintained through the nurturing of both exclusive tastes and prices, and the important role of commentators in nurturing discourses that lend both objects and makers a mythological aura of creative genius.

The opposing pole of this field marks a space where practitioners target a mass market or popular audience. In being exposed more explicitly to the logic of economic capital, this more contingent realm gives definition to the exclusivity of the autonomous realm. Craft objects produced for mass symbolic consumption may appear tacky, kitsch, cheap and vulgar to an elite audience, but this does not affect the symbolic value of such objects within groups to whom they have appeal. This also describes the function of craft works within practices of social distinction (Bourdieu 1984).

Importantly, the descriptions of each of these poles is not intended as a moral judgement itself, but as a description of the particular social space within 
which a practitioner works. Folding into this is the power of institutions such as galleries, universities, and the state, who each earn a symbolic profit as they support the 'social good' of the autonomous realm of production.

Amidst the social play of the field of symbolic production the most sustain-able characteristics of craft are obscured. As Neil Brown has argued, the dominance of semiotic theories, particularly within the world of fine arts, (mis)represent craft works as vessels of communication for ideas (Brown 1997: 14). Understanding the products of craft in terms of their sign value alone obscures the value of workmanship and denies the ontological conditioning that can occur during both fabrication and use. In a point supporting the damage done by semiotic aestheticism, Fry has also described how craft may be employed to counter 'modes of cultural and economic postmodernity, especially depersonalised post industrial corporate commodity culture and its accompanying"high" technology' - again treating craft as a reactionary form of symbolic resistance rather than something of more substance than mere sign (Fry 1994: 88).

Discourses on craft as symbolic objects have also undervalued the condition of craft as a form of industrial production. Reyner Banham for instance has argued for recognition of the craft nature of machine repair and maintenance (Banham 2008). While the wonder of 'machine precision' would appear to be based upon the elimination of human fallibility, ironically, it is the finesse and dexterity of highly skilled workers that have been key to countering the inevitable issues of wear and tear that occur within mechanised production (Banham 2008: 140). The flexible attunement of these workers is something beyond the capacity of any automated device. Banham also makes the point that the character of craft discourse often perpetuates a materials bias, arguing that an exclusive focus on 'craft' materials - such as wood, metals, textiles, ceramics, and glass - is unfounded. Banham cites the manufacture of hand-crafted fiberglass surfboards as a telling example of a significant practice of workmanship that is denied recognition despite being a highly developed tradition of skillful performance.

\section{Craft as an agent of change}

A point that underscores the arguments of Banham, Fry, and Brown, is that craft is disenfranchised so long as its value is only understood in terms of the signifying object. The virtue of an embodied involvement with a material is the sensitivity and thoughtfulness that develops as a mode ofbeing. Considering craft in terms of embodied skill opens up a world of practices (for example, cooking, gardening, weaving, ceramics, smithing, machining, panel beating, typesetting, leatherworking, carpentry, bricklaying, cobbling, tailoring, glass working, shipbuilding, surgery, and so on) that could one day form part of a condition of Sustainment.

What then stands in the way of craft becoming a truly effective force for Sustainment? In simple terms it is that practitioners work within economic, material, and symbolic structures that deny craft its sustaining power (Fry 1994). 
This occurs through the constitution of craft as a practice of aestheticised symbolic play, and an economic dynamic that prevents cultures of quality from forming the basis of our material culture. However, in working to change these conditions, there are characteristics of craft practice that, if politicised, may have potential to contribute to a transformative agenda.

For instance, craft knowledge exists as a socially conditioned form of judgement inscribed into the disposition of the practitioner and their world of equipment. This has two consequences. Being an embodied social practice, a culture of craft is developed by people who must be geographically near to each other in order to share and develop expertise. Secondly, because craft knowledge is inscribed in bodily dispositions, it is both non-propositional and time intensive. These characteristics - people, in close spatial relationship, slowly developing an expertise that is not easily dispersed - grate against the propensity of (post) modern capitalism to structure time, space, people and information into more flexible and convenient forms (Harvey 1990: 284).

These same antagonisms may also exist in relation to the consumption of craft. For instance, often the conditions for rich qualitative experiences are counter to the logic of instant or commodified gratification. If I am to appreciate a certain quality of food, clothing, or music, for instance, I must make time in my life to become a certain kind of connoisseur. While connoisseurship can foster the worst aspects of social differentiation and aestheticism (Bourdieu 1984; Fry 1988: 21 ), within a sustain-able culture of quality this form of expertise could become a part of the experience of pleasure, fulfillment, and the pursuit of excellence in ourselves and our everyday objects. The philosopher Albert Borgmann has developed a related concept of 'focal practices' (Borgmann 1984: 196). These are practices that use technological equipment to engage people in skilled but fulfilling activities, such as playing a musical instrument, gardening, or cooking, rather than simply providing easy to consume commodified experiences.

If these ideas are returned to Harvey's dialectical schema we can start to see a semblance of transformative possibility. While craft already incorporates a relation to nature, its ability to claim something durable from mere resource is yet to be properly exploited. Craft also incorporates a particular mode of production, and a relation to technology that fosters the value of living labour, as well as itself producing technological instruments to increase the sustainability of practices. In order to be fully realised as Sustainment, craft also must be constituted as a new cultural concept and supported by the (re)formation of social institutions to more formally support and legitimise newly formed sustainable practices of fabrication.

\section{Conclusion}

Craft practice stands in dialectical relation to the conditions within which it exists. Its nature and power is a reflection of broader social conditions, but it 
must also be viewed as an agent within the transformation of this social order. Under current conditions craft is constrained from realising its potential as a force for Sustainment because it occupies a position within fields of cultural production that misdirect its sustaining qualities. These fields retain valuable aspects of craft knowledge, inscribed with the living bodies of practitioners and their equipment, however they also negate the ability of craft to engender and support practices of care at a scale required for Sustainment.

However, paths towards new conditions of practice may only be constructed from within existing practices (Fry 2009: 223). A key point is that craft practitioners must not wait for the conditions to be right in order for their work to become a force for Sustainment, as such a condition could only be the product of a sustained politicised commitment. This task is made difficult not only because of present day economic conditions, but also through prevailing cultures and discourses on craft that obscure its sustaining potential. This being the case, an ongoing critical examination of the conditions of craft practice should form part of a (re)constructive project that asserts the value of craft from within more sustain-able practices of work and living. As such a project leads to the production of new knowledge, new relations between people, new conditions of production, new technologies, new institutional arrangements, new conceptions of space and time, and a new character of our everyday lives, craft practice will have earned the genuine power to shape the character of being-in-the world in the interests of Sustainment.

\section{Acknowledgements}

I would like to express my gratitude to those who assisted me in writing this paper, particularly Tara Andrews for valuable comments on an early draft, Kevin Murray for his patience and encouragement, and my two peer-reviewers for their considered thoughts and recommendations.

\section{Bibliography}

Banham, R., 2008, Sparks from a Plastic Anvil: The Craftsman in Technology. The Journal of Modern Craft, 1; 1, pp. 137-145.

Baudrillard, J., 1981, For a critique of the political economy of the sign. St. Louis: Telos Press.

Baudrillard, J., 1996, The system of objects. London, New York: Verso.

Borgmann, A., 1984, Technology and the character of contemporary life: a philosophical inquiry. Chicago: University of Chicago Press

Bourdieu, P., 1983, The field cultural production, or: the economic world reversed. Poetics, 12, 311-356. 
Bourdieu, P., 1984, Distinction: a social critique of the judgement of taste. London: Routledge \& Kegan Paul.

Brown, N., 1997, Theorising the crafts: new tricks of the trade. In S. Rowley, ed., Craft and Contemporary Theory, pp 3-17.

Fry, T., 1988, Design History Australia. Sydney: Hale \& Iremonger.

Fry, T., 1994, Green hands against dead knowledge. In Remakings: ecology, design, philosophy, Sydney: Envirobook, pp. 87-102.

Fry, T., 1999, A new design philosophy: an introduction to defuturing. Sydney: UNSW Press

Fry, T., 2004, The Sustainment and its dialectic. In A. Willis,ed., Design Philosophy Papers: Collection One, pp. 33-45. Ravensbourne, Qld.: Team D/E/S.

Fry, T., 2007a, Homelessness - a philosophical architecture. In A. Willis, ed., Design Philosophy Papers: Collection Three, pp. 19-28. Ravensbourne, Qld: Team D/E/S.

Fry, T., 2007b, Redirective practice: an elaboration. In Design Philosophy Papers, Issue 12007.

Fry, T., 2007c, Design, development \& questions of direction. In A. Willis. ed., Design Philosophy Papers: Collection Three, Ravensbourne, Qld: Team D/E/S, pp. 66-79.

Fry, T., 2009, Design futuring: sustainability, ethics and new practice. Sydney: UNSW Press.

Harvey, D., 1990, The condition of postmodernity: an enquiry into the origins of cultural change. Oxford UK, Cambridge, Mass.: Blackwell

Harvey, D., 2010, Organizing for the Anti-Capitalist Transition. Talk given at the World Social Forum 2010, Porto Alegre. http://davidharvey.org/2009/12/ organizing-for-the-anti-capitalist-transition/. Accessed 31/1/2010.

Heidegger, M., 1962, Being and time. London: SCM Press.

Hickey, G., 1997, Craft within a consuming society, in P. Dormer, ed., The Culture of Craft. Manchester: Manchester University Press, pp. 83-100.

Latour, B, 2005, Reassembling the social: an introduction to actor-networktheory. Oxford: Clarendon.

Long, C. and Sweet, J., 2006, Globalization, nationalism and World Heritage: Interpreting Luang Prabang. South East Asia Research, 14; 3, pp. 445-469. 
Manzini, E.,1995, Prometheus of the Everyday: The Ecology of the Artificial and the Designer's Responsibility in R .Buchanan \& V. Margolin eds Discovering Design Chicago: University of Chicago Press.

Marx, K., 1974, Capital, Volume 1. London: Everyman's Library.

Pye, D., 1971, The nature and art of workmanship. London: Cambridge University Press.

Tonkinwise, T., 2004, Beauty-in-use. In A Willis, ed., Design Philosophy Papers: Collection One. Ravensbourne, Qld: Team D/E/S, pp. 63-70.

Shove, S., Watson, M., Hand, M., and Ingram, J., 2007, The design of everyday life. Oxford, New York: Berg.

Stables, A., 2010, Making Meaning and Using Natural Resources: Education and Sustainability, in Journal of Philosophy of Education, 44; 1, pp. 137-151.

Verbeek, P. \& Kockelkoren, P., 1998, The things that matter. In Design Issues, 14; 3, pp. 28-42.

Willis, A., 2007, Ontological designing - laying the ground. In A. Willis, ed., Design Philosophy Papers: Collection Three, pp. 80-98. Ravensbourne, Qld: Team D/E/S. 